\title{
'||||||||||||||||||||||||||||||||||||||||||||||||||||||||||||||||||||.
}

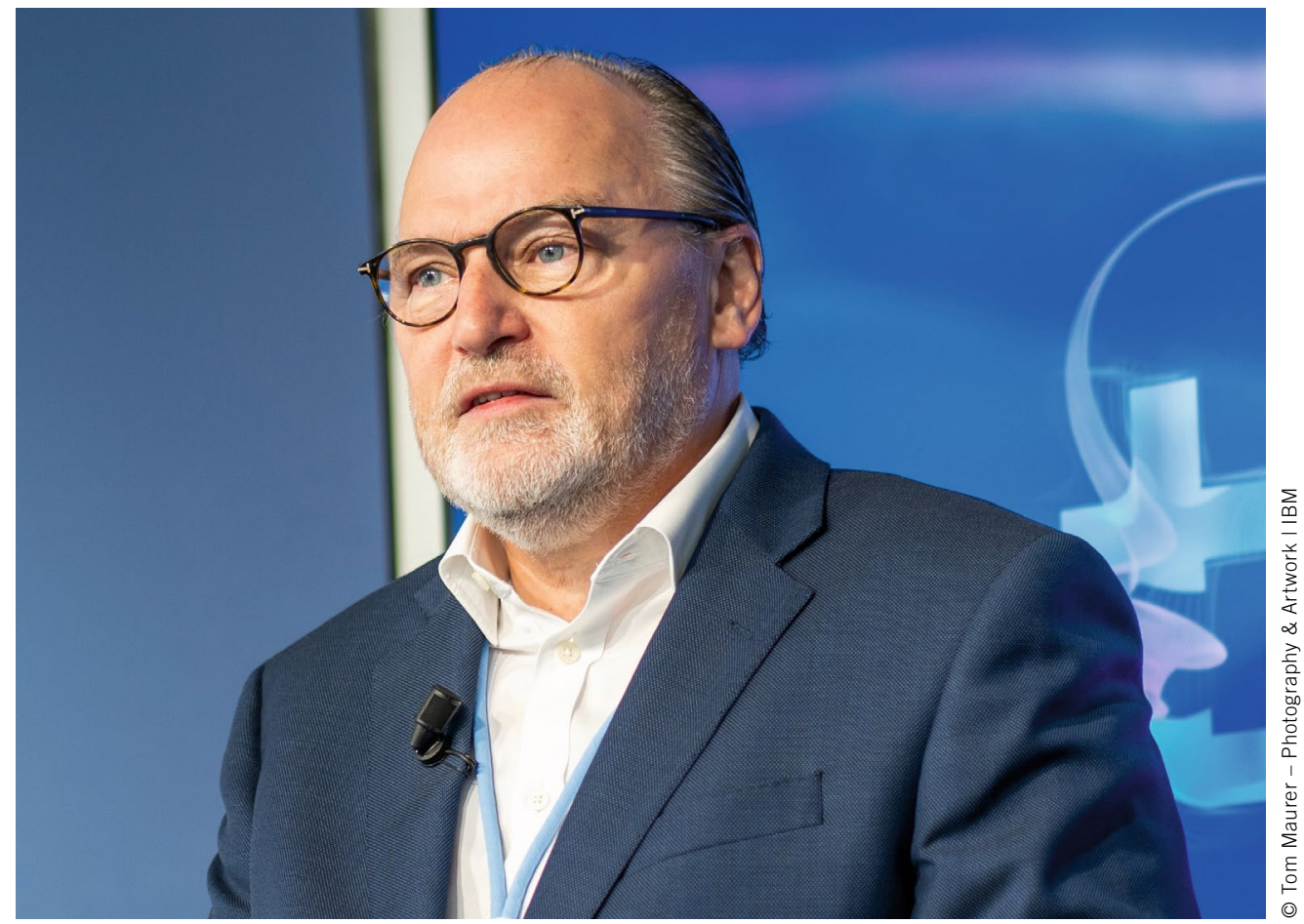

Dirk Wollschläger General Manager Global Automotive Industry at IBM Germany

\section{Mobility Study - This is What Moves Munich}

The political and social debate about the mobility transition is picking up speed. The reorientation of the IAA into a mobility trade fair, where different means of transport were presented in addition to (electric) cars is just one example of this shift. Another example is the ongoing discussion about electric mobility in general: a provocative topic. Critics get upset about charging times not being suitable for everyday use, while others express their concern about the actual sustainability of e-vehicles.

This has led IBM and market researcher Morning Consult to ask end customers about their attitudes toward sustainable mobility, e-cars, and their personal carbon footprint. A total of 1000 adults living in Munich expressed their opinions in a representative survey. A key result of this survey clearly shows that awareness for the need to act sustainably is high: $79 \%$ of respondents stated that their $\mathrm{CO}_{2}$ footprint is "important" (43\%) and even "very important" (36\%) to them. Unexpectedly though, the older generation pays more attention to their own footprint than the younger ones: $51 \%$ of respondents aged 65 and over consider their carbon footprint "very important," whereas among 18- to 34 -year-olds, it is only $30 \%$.

A person's carbon footprint is the decisive factor for only slightly more than half (56\%) when choosing daily transportation. Convenience and speed seem more important. Nevertheless, respondents aged 65 and over are twice as likely to con- sider sustainability aspects when choosing their transport compared to the 18-to-34-age group. And what do the respondents think about e-mobility? Overall, $58 \%$ consider e-vehicles to be environmentally friendly and sustainable. The younger age groups are more enthusiastic compared to the older ones: While $20 \%$ of the 18 - to 34 -year-olds "completely agree," only $6 \%$ of the over-65s agree. Among 35 - to 44 -year-olds, the figure is $16 \%$, and among 45- to 64-year-olds $10 \%$. Thus, as the age of the respondent's increases, the strong approval for electric vehicles decreases significantly.

Few people - only $7 \%$ - already own a personal e-vehicle. More than one third (39\%) are considering buying one in the next few years. More than half of the respondents (55\%) do not plan to buy one. The most important reason for not buying an electric car is the cost: For $36 \%$, the vehicle costs are simply (still) too high. Other reasons for not buying are doubts about the actual environmental impact of electric-powered vehicles (29\%), ethical concerns about battery supply chains (29\%), limited battery life (25\%), and limited availability of charging stations (23\%).

Addressing these concerns is critical in the transition from gasoline and diesel cars to e-vehicles. And because electric cars are a cornerstone for more sustainable mobility, IBM is supporting research into battery-powered alternatives for all sectors, right up to smart energy grids. 